University of Nebraska - Lincoln

DigitalCommons@University of Nebraska - Lincoln

\title{
Envelope protein complexes of Mycobacterium avium subsp. paratuberculosis and their antigenicity
}

\author{
Fernando L. Leite \\ lowa State University, Ames, fernando.leivasleite@gmail.com \\ Timothy A. Reinhardt \\ USDA, ARS, National Animal Disease Center, Tim.Reinhardt@ARS.USDA.GOV \\ J. P. Bannantine \\ USDA-ARS, National Animal Disease Center, john.bannantine@usda.gov \\ Judith R. Stabel \\ USDA-ARS, National Animal Disease Center, judy.stabel@ars.usda.gov
}

Follow this and additional works at: https://digitalcommons.unl.edu/usdaarsfacpub

Part of the Agriculture Commons

Leite, Fernando L.; Reinhardt, Timothy A.; Bannantine, J. P.; and Stabel, Judith R., "Envelope protein complexes of Mycobacterium avium subsp. paratuberculosis and their antigenicity" (2015). Publications from USDA-ARS / UNL Faculty. 2459.

https://digitalcommons.unl.edu/usdaarsfacpub/2459

This Article is brought to you for free and open access by the U.S. Department of Agriculture: Agricultural Research Service, Lincoln, Nebraska at DigitalCommons@University of Nebraska - Lincoln. It has been accepted for inclusion in Publications from USDA-ARS / UNL Faculty by an authorized administrator of DigitalCommons@University of Nebraska - Lincoln. 


\title{
Envelope protein complexes of Mycobacterium avium subsp. paratuberculosis and their antigenicity
}

\author{
Fernando L. Leite ${ }^{\mathrm{a}}$, Timothy A. Reinhardt ${ }^{\mathrm{b}}$, John P. Bannantine ${ }^{\mathrm{b}}$, \\ Judith R. Stabel ${ }^{\mathrm{b}, *}$ \\ a Iowa State University, Department of Veterinary Microbiology and Preventive Medicine, 2180 Veterinary Medicine, Iowa State University, \\ Ames, IA 50011, USA \\ ${ }^{\mathrm{b}}$ USDA-ARS, National Animal Disease Center, 1920 Dayton Avenue, Ames, IA 50010, USA
}

\section{A R T I C L E I N F O}

\section{Article history:}

Received 7 August 2014

Received in revised form 17 October 2014

Accepted 7 November 2014

\section{Keywords:}

Protein complexes

Mycobacterium avium subsp.

paratuberculosis

Antigens

\begin{abstract}
A B S T R A C T
Mycobacterium avium subsp. paratuberculosis (MAP) is the causative agent of Johne's disease, a chronic enteric disease of ruminant animals. In the present study, blue native PAGE electrophoresis and 2D SDS-PAGE were used to separate MAP envelope protein complexes, followed by mass spectrometry (MS) to identify individual proteins within the complexes. Identity of individual proteins within complexes was further confirmed by MS upon excision of spots from 2D SDS-PAGE gels. Among the seven putative membrane complexes observed, major membrane protein (MAP2121c), a key MAP antigen involved in invasion of epithelial cells, was found to form a complex with cysteine desulfurase (MAP2120c). Other complexes found included those involved in energy metabolism (succinate dehydrogenase complex) as well as a complex formed by $\mathrm{Cfp} 29$, a characterized $\mathrm{T}$ cell antigen of Mycobacterium tuberculosis. To determine antigenicity of proteins, Western blot was performed on replicate 2D SDS-PAGE gels with sera from noninfected control cows $(n=9)$ and naturally infected cows in the subclinical $(n=10)$ and clinical $(n=13)$ stages of infection. Clinical animals recognized MAP2121c in greater proportion than subclinical and control cows, whereas cysteine desulfurase recognition was not differentiated by infection status. To further characterize antigenicity, recombinant proteins were expressed for 10 of the proteins identified and evaluated in an interferongamma (IFN- $\gamma$ ) release assay as well as immunoblots. This study reveals the presence of protein complexes in the cell envelope of MAP, suggesting protein interactions in the envelope of this pathogen. Furthermore the identification of antigenic proteins with potential as diagnostic targets was characterized.
\end{abstract}

Published by Elsevier B.V.

\section{Introduction}

Mycobacterium avium subsp. paratuberculosis (MAP) is the causative agent of paratuberculosis (Johne's disease), a

\footnotetext{
* Corresponding author. Tel.: +1 515337 7304; fax: +1 5153377428.

E-mail addresses: fernando.leivasleite@gmail.com (F.L. Leite), tim.reinhardt@ars.usda.gov (T.A. Reinhardt), john.bannantine@ars.usda.gov (J.P. Bannantine), judy.stabel@ars.usda.gov (J.R. Stabel).
}

chronic enteric wasting disease of ruminant animals with worldwide distribution (Stabel, 1998; Sweeney, 2011). Paratuberculosis is predominantly a subclinical disease with economic impact primarily in dairy cattle in the US. As the disease progresses, there is a loss in milk production, as well as higher incidence of mastitis and infertility, leading to early culling of animals (Lombard, 2011). Currently, the diagnostics of MAP is based mainly upon the detection of the bacterium in feces by culture or PCR and by ELISA detection of MAP-specific antibodies. 
However, crude antigen preparations are used for antibody detection and these can limit the detection of asymptomatic animals. Detection of animals in the subclinical stage of infection can be difficult as these animals typically excrete MAP in low numbers and have not yet developed measurable antibody titers to MAP (Facciuolo et al., 2013; Scott et al., 2010). With this in mind, research to identify antigens that can be used to sensitively diagnose the disease is needed; in particular, antigens that are conducive for use in the IFN- $\gamma$ assay, a measure of Th1-mediated immune response elicited by animals in the subclinical stage of infection (Mortier et al., 2014; Stabel, 2006).

MAP is a member of the avium complex of mycobacteria and has an envelope comprised of a cytoplasmic membrane and a cell wall consisting of peptidoglycan, arabinogalactan, mycolic acids and proteins (Niederweis et al., 2010; He and De Buck, 2010). Proteins associated with the cell envelope of MAP are likely to be the first to interact with the host and, therefore, the first proteins for immune recognition (Kleinnijenhuis et al., 2011). Several antigenic proteins as well as those with roles in virulence have been found to be associated with the envelope of mycobacteria, including proteins of the PPE family (Deng and Xie, 2012). Thus, characterization of proteins present in the envelope is critical not only to the comprehension of the physiology and pathogenesis of the organism but also to identify potential antigenic proteins for use in vaccines and diagnostic assays.

In the present study, blue native (BN) PAGE and 2D SDSPAGE were used to characterize protein complexes in the envelope of MAP. BN PAGE is a technique that allows for the isolation of protein complexes with the use of non-ionic detergents allowing the solubilization of hydrophobic proteins that can be missed with other techniques such as iso-electric focusing (Dresler et al., 2011). Mass spectrometry was performed on blue native gels as well as 2D SDS-PAGE gels to identify proteins within complexes. To determine antigenicity of proteins, Western blot was performed on replicate 2D SDS-PAGE gels with sera from noninfected and naturally infected animals. Interferon gamma release assay was also performed with recombinant proteins, allowing for the identification of novel antigens with potential as vaccine and diagnostic targets.

\section{Materials and methods}

\subsection{Bacteria cell wall/membrane preparation}

A low passage clinical isolate of MAP, strain 509, was isolated from the jejunum of a cow manifesting clinical signs of paratuberculosis and was confirmed as MAP by IS900 and ISMAP02 PCR (data not shown). The bacterium was grown to log phase $\left(\mathrm{Abs}_{540 \mathrm{~nm}}=0.2-0.4\right)$ in Middlebrook 7H9 broth (pH 5.9) (Becton Dickinson) containing 0.05\% Tween 80 (Sigma) and ferric mycobactin J (2 mg/l; Allied Monitor), supplemented with oleic acid, albumin, dextrose, and catalase enrichment (OADC, BD). Cultures were pelleted by centrifugation at $10,000 \times \mathrm{g}$ for $30 \mathrm{~min}$ at $4{ }^{\circ} \mathrm{C}$ and washed twice with phosphate buffered saline (PBS). After the last centrifugation, pellets were stored at $-80^{\circ} \mathrm{C}$ until used for envelope extraction.
Cell wall/membrane preparation was performed as described in Radosevich et al. (2007) with some modifications. Sonication was performed in a hypotonic buffer (10 mM HEPES sodium salt, 1 mM EGTA, pH: 7.5, containing 1:100 protease inhibitor cocktail, Sigma). This was performed with seven sonication periods of 5 min each with a $90 \%$ duty cycle at output 1 , allowing for the sample to cool in between each sonication step. The sample was adjusted to $250 \mathrm{mM}$ sucrose and centrifuged at $10,000 \times \mathrm{g}$ for $30 \mathrm{~min}$ to remove unbroken cells and cellular debris. The supernatant was collected and centrifuged at $150,000 \times g$ for $1 \mathrm{~h}$ to isolate the cell wall/membrane. Other than a brief buffer wash no addition procedures were performed to these preparations in order to preserve protein complexes. Protein quantification was performed using the Bio-Rad protein assay (Bio-Rad Laboratories) and all samples were stored at $-20{ }^{\circ} \mathrm{C}$ until use.

\subsection{Blue native PAGE and 2D SDS-PAGE}

Separation of the protein complexes present within the cell wall and membrane of MAP was performed by blue native PAGE (Schägger and Jagow, 1991). Samples were solubilized by adding $100 \mu \mathrm{g}$ of protein to $100 \mu$ l nativePAGE sample buffer (Life Technologies) with $0.5 \%$ digitonin (Life Technologies) for $1 \mathrm{~h}$ at $4{ }^{\circ} \mathrm{C}$ in a rotating shaker. To remove insoluble protein, samples were centrifuged for 30 min at $14,000 \times g$ at $4{ }^{\circ} \mathrm{C}$. The resulting supernatant was combined with G-250 Coomassie in a final concentration corresponding to $25 \%$ of the detergent concentration. Extracts were loaded onto a 3-12\% native-PAGE gel (Life Technologies). Electrophoresis was performed in nativePAGE anode buffer (Life Technologies) and a cathode buffer containing $0.02 \% \mathrm{G}-250$ at $150 \mathrm{~V}$. When the dye front migrated halfway into the gel the cathode buffer was replaced with cathode buffer containing $0.002 \% \mathrm{G}-250$ for the remainder of the $3 \mathrm{~h}$ run.

Second dimension SDS-PAGE was performed as described by Schamel (2008), with some modifications. Gel strips were excised from the blue native gel and stored at $-20{ }^{\circ} \mathrm{C}$ until use. To denature protein complexes the gel strips were incubated in a solution of $2 \times$ SDS sample buffer and $2 \times$ NuPAGE sample reducing agent (Life Technologies) for $30 \mathrm{~min}$ at room temperature (RT) and incubated at $70{ }^{\circ} \mathrm{C}$ for another $30 \mathrm{~min}$. The strips were allowed to cool to RT for $30 \mathrm{~min}$. Each strip was then inserted into a single well $1.0 \mathrm{~mm} 4-12 \%$ Bis-Tris gel (Life Technologies). The strip was covered with $1 \times$ SDS sample buffer and $1 \times$ NuPAGE sample reducing agent. Electrophoresis was performed for $50 \mathrm{~min}$ at $200 \mathrm{~V}$ in MOPS buffer. Gels were stained using the SilverQuest silver stain kit (Life Technologies).

\subsection{Western-blot of 2D SDS-PAGE gels}

Electrophoretic transfer of proteins onto nitrocellulose was performed with a Trans Blot Cell (Bio-Rad Laboratories) with sodium phosphate buffer $(25 \mathrm{mM})$ at $0.9 \mathrm{~A}$ for $90 \mathrm{~min}$. After transfer, the membranes were blocked with PBS containing $0.1 \%$ Tween 20 (PBST) plus $2 \%$ bovine serum albumin (BSA) overnight at $4{ }^{\circ} \mathrm{C}$. Serum samples were 
diluted 1:200 in PBST with 2\% BSA and incubated for $2 \mathrm{~h}$ at RT. After the incubation, 3 washes were performed with PBST for 10 min each. Secondary antibody used was horse anti-goat IgG horse radish peroxidase conjugate (Vector Labs) at a dilution of 1:20,000 for $1 \mathrm{~h}$ of incubation. Following another 3 washes as described above, blots were incubated with SuperSignal West Pico Chemiluminescent Substrate (Thermo Fisher) for protein detection and exposed to X-ray film.

\subsection{Preparation of trypsin digests}

2D-SDS-PAGE and native PAGE gels stained with the SilverQuest silver stain kit were imaged using the Gel Doc EZ imaging system (Bio-Rad Laboratories). Identified spots (2D SDS-PAGE gels) or bands (native page gels) were excised from the gels and placed in siliconized tubes containing destaining buffer (solution of 30\% acetonitrile $(\mathrm{ACN})$ and $70 \%$ triethylammonium bicarbonate (TEABB)) and incubated at RT for $10 \mathrm{~min}$. Destaining buffer was removed and this step was repeated 3 times. The gel pieces were then dried in a vacuum centrifuge without heat. Next the gel pieces were rehydrated with a solution of $10 \mathrm{mM}$ TCEP (Tris (2-carboxyethyl)-phosphine) for $5 \mathrm{~min}$ at $4{ }^{\circ} \mathrm{C}$ then incubated in a $56{ }^{\circ} \mathrm{C}$ water bath for $1 \mathrm{~h}$. Alkylation was performed with a solution of $55 \mathrm{mM}$ iodoacetamide for $1 \mathrm{~h}$ at RT. Following incubation, the alkylation buffer was replaced with destaining buffer. For trypsin digestion, gel pieces were rehydrated with TEABB for $20 \mathrm{~min}$ at $4{ }^{\circ} \mathrm{C}$. Followed by another incubation at $90{ }^{\circ} \mathrm{C}$ for $20 \mathrm{~min}$ to heat denature proteins. After samples cooled to RT, one wash was performed with destaining buffer and the samples were dried in a vacuum centrifuge. A solution of proteomics grade trypsin $(20 \mu \mathrm{g} / \mathrm{ml}$; Sigma-Aldrich $)$ diluted in TEABB was added to cover the gel pieces and samples were incubated for $5 \mathrm{~min}$ at $4{ }^{\circ} \mathrm{C} \mathrm{A}$ solution of $60 \% \mathrm{TEABB} / 40 \% \mathrm{ACN}$ containing $25 \mu \mathrm{g} / \mathrm{ml}$ trypsin was used to cover the gel pieces and incubated overnight at $37^{\circ} \mathrm{C}$ in a shaking water bath. The next day the samples were cooled to RT. The digest solution was transferred to clean siliconized tubes. The gel slices were extracted $2 \times$ with 50:50 (v/v) ACN:5\% formic acid, $1 \times$ with 15:50:35 (v/v) isopropanol:ACN:5\% formic acid, and $2 \times$ with $80 \%$ ACN. All extracts were combined with the digest solution and dried in a vacuum centrifuge. The samples were stored dry at $-20^{\circ} \mathrm{C}$ until used.

\subsection{Online peptide chromatography and mass spectroscopy}

Samples were separated on a Proxeon Easy-nLC (Thermo Fisher Scientific), C18, $3 \mu \mathrm{m}, 75 \mu \mathrm{m} \times 100 \mathrm{~mm}$ column in mobile phase $\mathrm{A}\left(95 \% \mathrm{H}_{2} \mathrm{O}: 5 \%\right.$ acetonitrile and $0.1 \%$ formic acid) and mobile phase B (5\% $\mathrm{H}_{2} \mathrm{O}: 95 \%$ acetonitrile and $0.1 \%$ formic acid) gradient, $0 \% \mathrm{~B}$ for $9 \mathrm{~min}, 6-15 \%$ B from 10 to $80 \mathrm{~min}, 15-30 \%$ B from 80 to $88 \mathrm{~min}, 30-90 \%$ B from 88 to $90 \mathrm{~min}$, at $300 \mathrm{nl} / \mathrm{min}$. The analytical column was connected to a Proxeon Nanospray Flex Ion Source (Thermo Fisher Scientific) on the front end of a LTQ OrbiTrap Velos (Thermo Fisher Scientific) mass spectrophotometer. The capillary temperature was set at $275^{\circ} \mathrm{C}$ and spray voltage optimized using the API stability evaluation software for the LTQ OrbiTrap Velos. Data dependent method settings were as follows: FTMS was 60,000 resolution from 300 to $2000 \mathrm{~m} / z$ followed by up to 10 ion trap MSMS scans. Activation was CID using normalized collision energy of 35. Minimal signal required was 5000 and repeat mass exclusion duration of $60 \mathrm{~s}$ (Reinhardt et al., 2012).

\subsection{Protein identification}

Tandem mass spectra were extracted by Protein Discoverer version 1.3.0.339. Charge state deconvolution and deisotoping were not performed. All MS/MS samples were analyzed Sequest (Thermo Fisher Scientific; version 1.3.0.339) and X! Tandem (The GPM, thegpm.org; version CYCLONE (2010.12.01.1). X! Tandem was set up to search the SP-MAP1770_120619.fasta (7368 entries) assuming trypsin cleavage. Sequest was set up to search SP-MAP17 70_120619.fasta (7368 entries) also assuming trypsin cleavage. Sequest and X! Tandem were searched with a fragment ion mass tolerance of $0.08 \mathrm{Da}$ and a parent ion tolerance of 10.0 PPM. Iodoacetamide derivative of cysteine were specified in Sequest and X! Tandem as fixed modifications. Oxidation of methionine was specified in Sequest and $\mathrm{X}$ ! Tandem as a variable modification. Peptide and protein false discovery rates were $0.1 \%$ and $0.1 \%$ respectively with Scaffold probabilities set at 99\% for protein and 95\% for peptide identification.

Scaffold (version Scaffold_3.6.5, Proteome Software Inc.) was used to validate MS/MS based peptide and protein identifications. Peptide identifications were accepted if they could be established at greater than $95.0 \%$ probability as specified by the Peptide Prophet algorithm (Keller et al., 2002). Protein identifications were accepted if they could be established at greater than $99.0 \%$ probability and contained at least 2 identified peptides. Protein probabilities were assigned by the Protein Prophet algorithm (Nesvizhskii et al., 2003). Proteins that contained similar peptides and could not be differentiated based on MS/MS analysis alone were grouped to satisfy the principles of parsimony.

Predictions of trans-membrane topology were conducted using the TMHMM 2.0 program, publicly available from the Centre for Biological Sequence Analysis at the Technical University of Denmark http://www.cbs.dtu.dk/ services/TMHMM/. Functional association prediction between identified proteins was analyzed using STRING version 9.05 interaction database http://string-db.org/.

\subsection{Cloning of M. avium subsp. paratuberculosis coding sequences}

Proteins that were identified by MS from 2D SDS PAGE gels and demonstrated antigenicity on Western blot analyses were cloned and expressed following protocols previously described (Bannantine et al., 2010). The pMAL protein fusion and purification system was used with the pMAL-c2x expression vector (New England Biolabs). After identification of the proteins of interest, the corresponding coding sequences were amplified from the annotated MAP genome (Li et al., 2005). Primers were designed for the n-terminal and c-terminal portions of the proteins to span 
their whole coding sequence, Xbal and HindIII restriction sites were added to the $5^{\prime}$ and $3^{\prime}$ primers respectively to allow digestion and insertion into the expression vector. The protein cysteine desulfurase (MAP2120c) had to be cloned in two fragments because its size was too large (2013 kb) for full-length amplification and cloning. Amplification of the desired DNA sequences for insertion into the expression vector was performed using a master mix containing $20 \mu \mathrm{l}$ GC Melt Buffer $2 \times$ Advantage (Clontech), $1 \mu$ l each of forward and reverse primers, $1 \mu \mathrm{K}$-10 genome template, $0.2 \mu \mathrm{l}$ polymerase, $20 \mu \mathrm{l}$ distilled water and $2 \mu \mathrm{l}$ dNTP nucleotide mix (Roche). PCR products were purified using the Gene Clean Turbo kit (Q-Biogene) and digested for $1 \mathrm{~h}$ at $37^{\circ} \mathrm{C}$ with XbaI and Hind III enzymes (New England Biolabs). Following purification with the Gene Clean Turbo kit, ligation was performed overnight at $16{ }^{\circ} \mathrm{C}$ with T4 ligase and T4 ligase buffer (New England Biolabs). Escherichia coli DH5$\alpha$ was transformed by heat shock and incubated overnight in LB agar containing carbenicillin. To confirm transformation and ligation, 8 colonies from each agar plate were screened for the protein coding sequence of interest by PCR. One colony from each plate confirmed by PCR to have the cloned plasmid was further amplified by overnight culture in LB broth containing glucose $(0.2 \%)$ and carbenicillin $(100 \mathrm{mg} / \mathrm{ml})$. Sequencing of cloned plasmids was performed to confirm in-frame insertion of the coding sequence to the $3^{\prime}$ end of the malE gene in the vector, which encodes maltose-binding protein (MBP) allowing for protein purification by affinity chromatography.

\subsection{Protein expression and purification}

Protein expression and purification followed protocols previously described (Bannantine et al., 2006, 2010). Using the pMAL protein fusion and purification system (New England Biolabs), overnight cultures of cloned E. coli DH5- $\alpha$ were inoculated into 21 flasks containing 11 of LB broth supplemented with glucose $(0.2 \%)$ and carbenicillin $(100 \mu \mathrm{g} / \mathrm{ml})$ and cultured in a rotary shaker at $37^{\circ} \mathrm{C}$. When an $\mathrm{OD}_{600 \mathrm{~nm}}$ of $0.4-0.6$ was reached, cells were induced by incubation with $360 \mu \mathrm{l}$ of $1 \mathrm{M}$ isopropyl-1-thio- $\beta$-D-galactoside (IPTG) solution for $2 \mathrm{~h}$. After induction, cells were pelleted by centrifugation and resuspended in column buffer (20 mM TrisCl, $1 \mathrm{mM}$ EDTA, $\mathrm{pH} 7.4)$ and stored overnight at $-20^{\circ} \mathrm{C}$. Upon thawing of cells, sonication was performed for $4 \mathrm{~min}$ in an ice bath and the lysate was clarified by centrifugation. For purification of the fusion protein, affinity chromatography was performed using an amylose resin column. Protein was eluted with column buffer containing $10 \mathrm{mM}$ maltose. Eluted protein was dialyzed in $11 \mathrm{PBS}$ at $4^{\circ} \mathrm{C}$ with three exchanges using $10 \mathrm{~K}$ molecular weight cut off dialysis cassettes (Thermo Fisher). Purified proteins were analyzed by SDS-PAGE gels stained with GelCode Blue (Thermo Fisher) and quantified by the Bio-Rad protein assay (Bio-Rad Laboratories) for later use in immunoblots and the IFN- $\gamma$ release assay.

\subsection{Immunologic assays}

Serum and whole blood samples were obtained for immunologic assays from naturally infected Holstein dairy cows ranging in age from 3 to 9 years of age. Cows were stratified into infection groups by monitoring fecal shedding of MAP by culture and PCR as previously described (Khalifeh et al., 2009). By definition, clinical cows were shedding more than 100 CFU per $g$ of feces and presented with weight loss and intermittent diarrhea. Subclinically infected cows were shedding less than $10 \mathrm{CFU} / \mathrm{g}$ of feces and were asymptomatic. Noninfected control cows were characterized by repeated negative fecal culture performed semi-annually over a 3-5-year period. In addition, these animals were negative for production of antibodies specific for MAP and interferon- $\gamma$ performed during that period. All animals were housed in American Association for Accreditation of Laboratory Animal Care-accredited facilities and all animal related procedures were approved by the IACUC (National Animal Disease Center, Ames, IA). Cows presenting with disease were housed separately on-site from healthy control cows to prevent cross-contamination between groups.

For immunoblots, $12 \%$ SDS-polyacrylamide gels were cast with two lanes, one long lane across the top of the gel and another for loading protein size standard. A $100 \mu \mathrm{l}$ aliquot of recombinant protein $(4.5 \mu \mathrm{g}$ total) was loaded to the long lane and the gel submitted to electrophoresis. The subsequent steps used for transfer to nitrocellulose are essentially those of the Western blot on 2D SDS-PAGE described above. The nitrocellulose blot was placed into a slot-blot device (Bio-Rad Laboratories) and individual serum samples were loaded into independent slots on the device. After $2 \mathrm{~h}$, the slots were washed in PBS-T, the device was disassembled and the nitrocellulose blot was placed in a tray containing PBS-T for additional washes. Blots were incubated with secondary antibody for $90 \mathrm{~min}$ and after washing with PBS-T were incubated with SuperSignal West Pico Chemiluminescent substrate (Thermo Fisher) for protein detection and exposed to X-ray film. Band intensities were measured using Image J software by the National Institutes of Health http://rsbweb.nih.gov/ij/. In the case of a recombinant protein demonstrating more than one band of similar molecular weight, both were considered when calculating in band intensities.

Whole heparinized blood was added in $300 \mu$ l volume to each well of a 96-well plate to evaluate the IFN- $\gamma$ response to each recombinant protein. In addition, a whole-cell sonicate preparation and an envelope fraction of MAP were also added for comparison of protein reactivity in the assay and as controls to assess animal infection status. Concanavalin A (ConA; Sigma) and pokeweed mitogen (PWM; Sigma) were used as positive controls to validate cell reactivity. Each protein was tested in the concentrations of 10,5 and $2.5 \mu \mathrm{g} / \mathrm{ml}$ and incubated for $18 \mathrm{~h}$ at $39{ }^{\circ} \mathrm{C}$ in a humidified atmosphere with $5 \%$ $\mathrm{CO}_{2}$. After incubation, plates were centrifuged for $5 \mathrm{~min}$ at $2500 \times g$ and plasma samples were harvested to measure secreted IFN- $\gamma$. The Bovigam ${ }^{\circledR}$ (Prionics, La Vista, NE) ELISA assay was used to measure IFN- $\gamma$ levels in antigenstimulated plasma as described by the manufacturer. Absorbance readings $(450 \mathrm{~nm})$ of responses to proteins were corrected for background responses to MBP and nil medium responses. 


\subsection{Statistical analyses}

Data analysis was performed using SAS 9.3 (SAS Institute Inc.). To analyze 2D Western-blot data, Fisher's exact test was used. IFN- $\gamma$ and slot blot results were analyzed with a one-way ANOVA and linear combinations of means.

\section{Results}

\subsection{Identification of protein complexes}

In this study, a total of 7 putative protein complexes were observed in blue native PAGE gels, ranging from molecular weights of 119-996 kDa (Fig. 1). Complexes I, II and $\mathrm{V}$ were most readily observed following Coomassie staining (Fig. 1). To identify the proteins present within each complex, complexes were denatured and run on 2D SDS-PAGE gels, but low resolution of proteins in 2D SDSPAGE gels necessitated further optimization. Optimal results were obtained after samples were dialyzed and treated with benzonase to remove nucleic acids prior to running BN gels for subsequent 2D SDS-PAGE (data not shown). Several protocols were attempted to perform 2D SDS-PAGE, with the best protocol being a modification of that published by Schamel (2008), requiring pre-incubation of samples in a $70^{\circ} \mathrm{C}$ water bath. Identification of proteins within complexes was performed by MS of excised bands from blue native gels (Fig. 1 and Table 1) and spots observed on 2D SDS-PAGE gels (Fig. 2). A total of

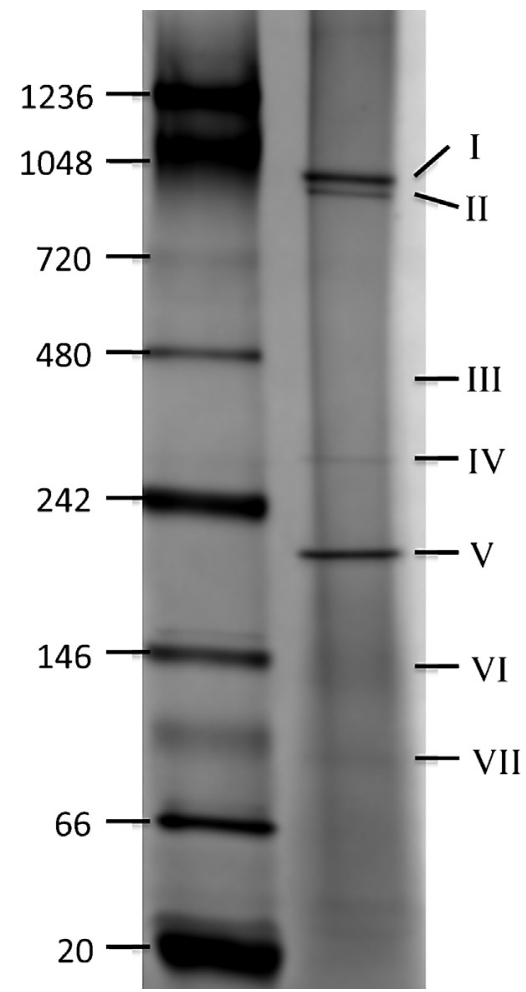

Fig. 1. Blue native gel stained with Coomassie blue demonstrating the different complexes found in MAP cell envelope preparations. Left lane is molecular weight standards in kDa. Right lane is MAP protein complexes.
29 spots were observed on 2D SDS-PAGE gels, 13 of which could be identified by MS (Table 2).

A summary of proteins found in each putative complex can be found in Table 1. Complex I was comprised of a cysteine desulfurase (MAP2120c) and major membrane protein (MAP2121c). This was confirmed by MS analysis of the representative band on the blue native gel (Table 1) as well as spots corresponding to the proteins found on the 2D SDS-PAGE gel (Fig. 2 and Table 2). Complex II was comprised of several proteins. Cfp29 (MAP0630c) was found in this complex along with a Dyp-type peroxidase family protein (MAP0631c). Other proteins found in complex 2 are involved in protein transport such as members of the Sec pathway (Sec D, $\times$ Sec F) and members of the $A B C$ transport system.

Members of the succinate dehydrogenase complex were found in complex III. Here the flavoprotein and iron-sulfur protein subunits of the complex, encoded by MAP3698c and MAP3967c respectively, were found. In complex VI, the protein glutamine synthetase (MAP1962) was observed to form a complex. Finally, complex VII was comprised of proteins involved in fatty acid synthesis, FadA2 (MAP3693), FadD15 (MAP1925) and FabG4 (MAP3692c).

Interactions of proteins within complexes were predicted by String 9.05 analyses. Among them were major membrane protein (MAP2121c) and cysteine desulfurase (MAP2120c) found in complex I (Fig. 3). Others included Cfp29 (MAP0630c) and a dyp-type peroxidase family protein (MAP0631c) found in complex II and the proteins in complex VII, FadA2 (MAP3693), FadD15 (MAP1925) and FabG4 (MAP3692c) (Fig. 3).

\subsection{Protein antigenicity by Western blot and IFN- $\gamma$}

To identify antigenic proteins present within the envelope compartment of MAP, Western blots were performed using sera from 13 clinical, 9 subclinical and 10 control noninfected animals. Fig. 4 contains immune blots representative of each infection stage of Johne's disease and serum reactivity for each protein is summarized in Table 3. Cysteine desulfurase (MAP2120c) garnered the most reactivity among all animals, reacting with sera from all clinical and control animals as well as $77.8 \%$ of subclinical animals. Several other proteins demonstrated antigenicity dependent upon the animal's stage of infection. Major membrane protein (MAP2121c) was recognized by $61.5 \%$ of animals with clinical paratuberculosis as opposed to $10 \%$ of control animals $(P<0.05)$ and $22.2 \%$ of subclinical animals. Interestingly, linocin/cfp29 (MAP0630c) had an opposite pattern of reactivity with $40 \%$ of control animals demonstrating antibodies to the protein in comparison to $7.6 \%$ of animals in the clinical stage of disease. Bacterioferritin (MAP1595c) was also found to be a strong, but not specific antigen showing reactivity in $92.3 \%$ of clinical, $55.6 \%$ of subclinical and $60 \%$ of control animals.

Further evaluation of recombinant proteins in an IFN- $\gamma$ assay demonstrated potential to discriminate animals in the early stage of infection. Most proteins demonstrated significantly $(P<0.05)$ greater response in subclinically 
Table 1

Summary of proteins identified by MS/MS in each complex (see Fig. 1) of first dimension blue native gel.

\begin{tabular}{|c|c|c|c|c|c|c|}
\hline Protein description & Gene & $\begin{array}{l}\text { Protein } \\
\text { MW (kDa) }\end{array}$ & $\begin{array}{l}\text { Total } \\
\text { number } \\
\text { of spectra }\end{array}$ & $\begin{array}{l}\text { Number } \\
\text { of unique } \\
\text { peptides }\end{array}$ & $\begin{array}{l}\text { Percent } \\
\text { sequence } \\
\text { coverage }\end{array}$ & $\begin{array}{l}\text { Predicted } \\
\text { trans-membrane } \\
\text { helices }^{\mathrm{a}}\end{array}$ \\
\hline \multicolumn{7}{|l|}{ Complex I } \\
\hline Major membrane protein ${ }^{\mathrm{b}}$ & MAP2121c & 34 & 71 & 14 & 61.90 & 0 \\
\hline Probable cysteine desulfurase ${ }^{b}$ & MAP2120c & 72 & 58 & 13 & 34.30 & 0 \\
\hline \multicolumn{7}{|l|}{ Complex II } \\
\hline Linocin/Cfp $29^{\mathrm{b}}$ & MAP0630c & 29 & 110 & 17 & 76.20 & 0 \\
\hline Dyp-type peroxidase family & MAP0631c & 36 & 16 & 4 & 20.20 & 0 \\
\hline $\begin{array}{l}\text { Putative RND superfamily } \\
\text { drug exporter }\end{array}$ & MAP3641c & 102 & 9 & 3 & 2.51 & 10 \\
\hline $\begin{array}{l}\text { Putative exporter of } \\
\text { polyketide antibiotics }^{\mathrm{b}}\end{array}$ & MAP2561 & 56 & 5 & 2 & 6.03 & 12 \\
\hline $\begin{array}{l}\text { Protein translocase } \\
\text { subunit } \mathrm{SecF}^{\mathrm{b}}\end{array}$ & MAP1044 & 46 & 6 & 2 & 9.66 & 6 \\
\hline $\begin{array}{l}\text { ABC-type multidrug transport } \\
\text { system, ATPase component }\end{array}$ & MAP3465 & 85 & 5 & 2 & 3.41 & 6 \\
\hline $\begin{array}{l}\text { Daunorubicin resistance } \\
\text { ABC transporter } \\
\text { ATP-binding subunit }\end{array}$ & MAP1238c & 33 & 4 & 2 & 6.98 & 0 \\
\hline $\begin{array}{l}\text { Arabinose efflux } \\
\text { permease family protein }\end{array}$ & MAP1596 & 72 & 3 & 2 & 4.70 & 13 \\
\hline Transport protein & MAP1240c & 105 & 2 & 2 & 2.28 & 12 \\
\hline \multicolumn{7}{|l|}{ Complex III } \\
\hline $\begin{array}{l}\text { Succinate dehydrogenase/fumarate } \\
\text { reductase flavoprotein subunit }\end{array}$ & MAP3698c & 71 & 86 & 22 & 38.50 & 0 \\
\hline FadA2 & МАР3693 & 47 & 14 & 3 & 11.60 & 0 \\
\hline $\begin{array}{l}\text { Succinate dehydrogenase } \\
\text { and fumarate reductase } \\
\text { iron-sulfur protein }{ }^{\mathrm{b}}\end{array}$ & MAP3697c & 29 & 29 & 8 & 37.90 & 0 \\
\hline $\mathrm{SppA}^{\mathrm{b}}$ & MAP4188 & 63 & 37 & 11 & 26.20 & 0 \\
\hline Putative uncharacterized protein & MAP3699c & 32 & 8 & 3 & 12.00 & 5 \\
\hline \multicolumn{7}{|l|}{ Complex IV } \\
\hline $\begin{array}{l}\text { Succinate dehydrogenase, } \\
\text { flavoprotein subunit }^{\text {b }}\end{array}$ & MAP3443 & 64 & 15 & 4 & 7.02 & 0 \\
\hline Rieske Fe-S protein ${ }^{\mathrm{b}}$ & MAP1934 & 44 & 11 & 3 & 11.70 & 3 \\
\hline $\begin{array}{l}\text { 3-Oxoacyl-(Acyl-carrier } \\
\text { protein) reductase }^{\mathrm{b}}\end{array}$ & MAP2332c & 328 & 4 & 2 & 0.84 & 0 \\
\hline $\begin{array}{l}\text { Glycerol-3-phosphate } \\
\text { dehydrogenase }^{\text {b }}\end{array}$ & MAP3423c & 63 & 5 & 3 & 5.14 & 0 \\
\hline $\begin{array}{l}\text { Preprotein translocase, } \\
\text { SecE subunit }\end{array}$ & MAP4110 & 16 & 5 & 2 & 15.60 & 1 \\
\hline \multicolumn{7}{|l|}{ Complex V } \\
\hline Bacterioferritin & MAP1595 & 18 & 45 & 9 & 61.60 & 0 \\
\hline Isocitrate lyase $\mathrm{b}^{\mathrm{b}}$ & MAP1643 & 85 & 26 & 10 & 17.20 & 0 \\
\hline Fe-S oxidoreductase ${ }^{\mathrm{b}}$ & MAP3831c & 103 & 12 & 3 & 5.42 & 5 \\
\hline Putative uncharacterized protein ${ }^{\mathrm{b}}$ & MAP0212 & 70 & 28 & 7 & 15.90 & 2 \\
\hline Pyridoxal biosynthesis lyase PdxS & MAP2710c & 32 & 17 & 5 & 23.10 & 0 \\
\hline Putative membrane protein & MAP1016c & 65 & 9 & 2 & 3.70 & 5 \\
\hline Putative uncharacterized protein & MAP1689 & 44 & 6 & 3 & 9.98 & 0 \\
\hline \multicolumn{7}{|l|}{ Complex VI } \\
\hline Glutamine synthetase ${ }^{\mathrm{b}}$ & MAP1962 & 54 & 20 & 6 & 19.00 & 0 \\
\hline \multicolumn{7}{|l|}{ Complex VII } \\
\hline FadA2 $^{\mathrm{b}}$ & MAP3693 & 47 & 31 & 8 & 24.80 & 0 \\
\hline FadD $15^{\mathrm{b}}$ & MAP1925 & 65 & 13 & 3 & 7.33 & 0 \\
\hline FabG4 & MAP3692c & 47 & 11 & 3 & 10.40 & 0 \\
\hline FadE25_2 & MAP0150c & 44 & 202 & 17 & 54.30 & 0 \\
\hline FadE3 & MAP3651c & 41 & 4 & 2 & 8.38 & 0 \\
\hline Putative uncharacterized protein ${ }^{\mathrm{b}}$ & MAP3972c & 37 & 8 & 2 & 11.40 & 1 \\
\hline ATP synthase subunit alpha & MAP2453c & 60 & 9 & 3 & 9.03 & 0 \\
\hline Glycosidase & MAP2433 & 77 & 18 & 6 & 12.50 & 0 \\
\hline 22 kDa lipoprotein & MAP1138c & 24 & 17 & 4 & 21.80 & 0 \\
\hline
\end{tabular}

a http://www.cbs.dtu.dk/services/TMHMM-2.0/.

b Gel diffusion was observed with some proteins being found in more than one complex. Proteins were assigned to complexes based upon the presence in that band and higher number of spectra present within the assigned band. The full list of all identified proteins and three replicate MS runs can be found in supplemental file S1. 


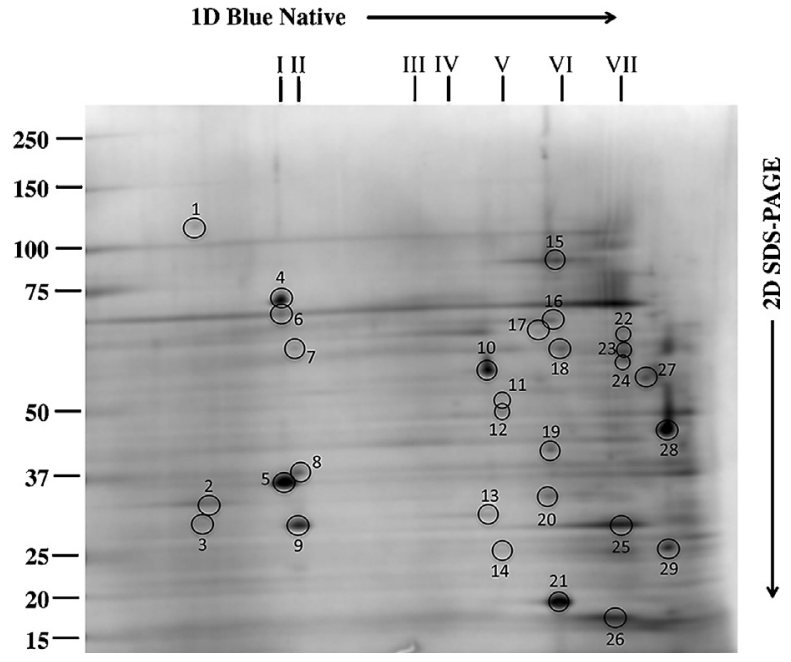

Fig. 2. Resolution of blue native protein complexes by SDS-PAGE gel. Roman numerals on top of gel indicate 7 protein complexes present in blue native gel. Circled are spots identified by MS.

infected animals compared to responses in control noninfected animals and clinical cows (Fig. 5). The proteins with the highest reactivity were cysteine desulfurase (MAP2120c) and phage shock protein A (MAP2855), followed by Cfp29/linocin (MAP0630c) and the $22 \mathrm{kDa}$ putative lipoprotein (MAP1138). Clinical animals in general had low reactivity to proteins, with the greatest reactivity being observed for phage shock protein $A$ (MAP2855c). Control animals had low OD readings to most proteins, and the highest reactivity was observed for the $22 \mathrm{kDa}$ lipoprotein (MAP1138).

\subsection{Protein antigenicity by cow infection status}

Immunoblots were performed with the recombinant proteins in an attempt to determine their antigenicity in the context of infection. In this analysis, several proteins demonstrated higher band intensities among the clinical group as compared to control animals and subclinical animals (Table 4). This is evident by the contrasting band intensities between these groups of proteins, Acyl-CoA dehydrogenase (MAP0150) $(P<0.05)$ and a $22 \mathrm{kDa}$ lipoprotein (MAP1138c) $(P<0.05)$. Clinical animals had an average band intensity of 3402 for Acyl-CoA dehydrogenase, while the corresponding values in the control and subclinical groups were 413 and 455, respectfully. For the $22 \mathrm{kDa}$ lipoprotein, the average among clinical animals was 708, as compared to the control group with an average of 2 . In general, subclinical animals had low band intensity indicating negligible antibody to these proteins. Two exceptions were phage shock protein A (MAP2855c), with an average band intensity of 1706 and putative ATPase (MAP3844) with a band intensity of 1506.

\section{Discussion}

Using blue native PAGE and MS, putative membrane protein complexes of MAP were found and component proteins identified. This is the first study to characterize protein complexes in the envelope of MAP. Proteins that are co-located in a single protein complex can be reasonably thought of as interacting with one another at some level. Some interactions are fairly obvious, such as the MAP3698c and MAP3697c, which both encode subunits of the succinate dehydrogenase complex. Others need to be studied further to understand what the interaction means biologically (i.e. MAP2120c and MAP2121c). In this study, a total of seven putative protein complexes were identified. These results add another layer of detail to the organization of the mycobacterial cell wall.

Complex I was found to contain major membrane protein (MMP) encoded by MAP2121c, a characterized surface exposed protein of MAP. MMP has been shown to be involved in invasion of epithelial cells by MAP and to be recognized by sera of animals with paratuberculosis (Bannantine et al., 2003). Here we show that MMP forms a protein complex with a probable cysteine desulfurase (MAP2120c), an enzyme that removes elemental sulfur from cysteine for biosynthesis of a variety of co-factors (Mihara and Esaki, 2002). This enzyme is classified as a group II desulfurase based on the consensus sequence

Table 2

Proteins spots identified by MS/MS on 2D SDS-PAGE gels. ${ }^{a}$

\begin{tabular}{|c|c|c|c|c|c|}
\hline Spot ID & Protein description & Gene & $\begin{array}{l}\text { Protein } \\
\text { MW (kDa) }\end{array}$ & $\begin{array}{l}\text { Number of } \\
\text { unique peptides }\end{array}$ & $\begin{array}{l}\text { Percent sequence } \\
\text { coverage }\end{array}$ \\
\hline 2 & Phage shock protein $\mathrm{A}$ & MAP2855c & 29 & 2 & 10.50 \\
\hline 4 & Probable cysteine desulfurase & MAP2120c & 71 & 3 & 7.60 \\
\hline 5 & Major membrane protein & MAP2121c & 33 & 8 & 38.10 \\
\hline 9 & Linocin/CFP29 & MAP0630c & 28 & 4 & 16.60 \\
\hline 10 & Putative uncharacterized protein & MAP3290c & 21 & 2 & 13.20 \\
\hline 15 & Acyl-CoA dehydrogenase & MAP4214c & 41 & 2 & 16.30 \\
\hline 17 & Non-ribosomal peptide synthase & MAP3482 & 73 & 2 & 3.65 \\
\hline 18 & grpE & MAP3841 & 23 & 2 & 28.60 \\
\hline 20 & Putative ATPase & MAP3844 & 154 & 2 & 2.44 \\
\hline 21 & Bacterioferritin & MAP1595 & 18 & 7 & 58.50 \\
\hline 23 & Adenosine deaminase & MAP2443 & 54 & 2 & 8.08 \\
\hline 25 & $\begin{array}{l}\text { Methyltransferase, cyclopropane } \\
\text { fatty acid synthase }\end{array}$ & MAP3963 & 32 & 2 & 13.60 \\
\hline 28 & Acyl-CoA dehydrogenase & MAP0150c & 43 & 3 & 8.44 \\
\hline
\end{tabular}

a See Fig. 2 for spot locations on 2D SDS-PAGE gels. 

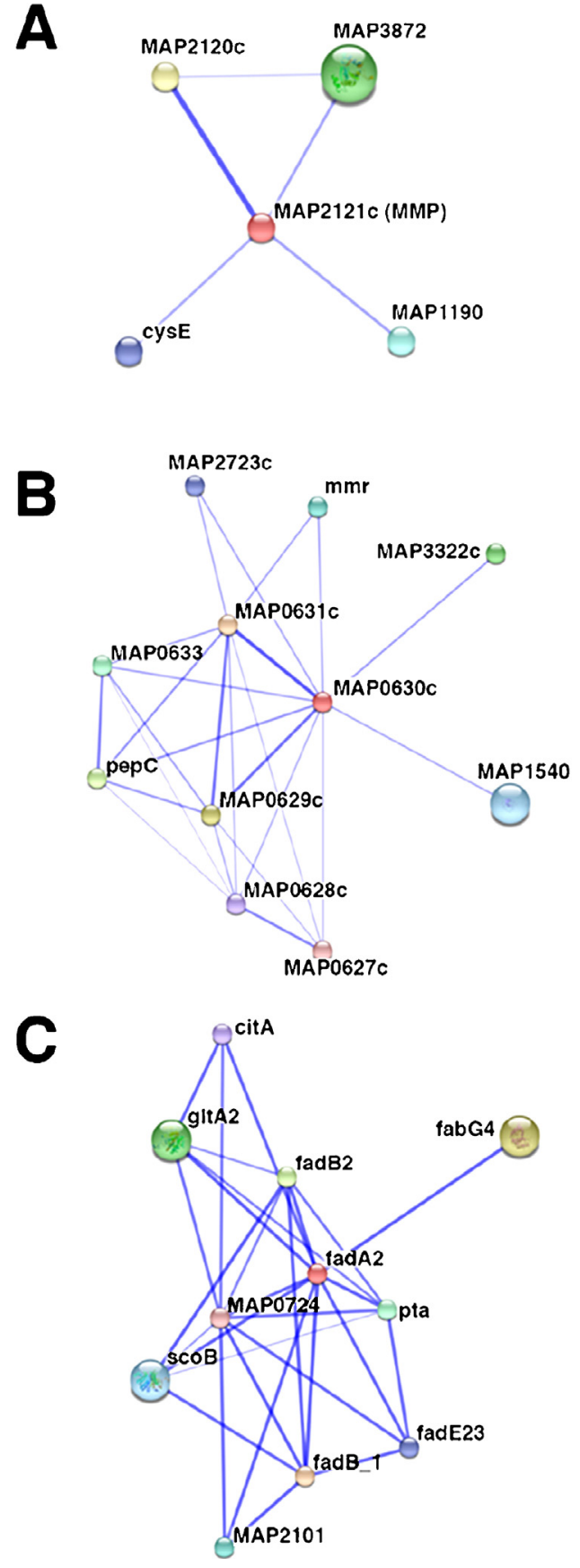

Fig. 3. Confidence view generated by String 9.05 software of interaction between (A) probable cysteine desulfurase (MAP2120c) and major membrane protein (mmpI), (B) Cfp29 (MAP0630c) and Dyp-type peroxidase family protein (MAP0631C), (C) FadA2 (MAP3693), FadD15 (MAP1925) and FabG4 (MAP3692c). The strength of the predicted association between proteins is represented by the thickness of lines.

(RAGHHCA) around the conserved Cys625 (Mihara and Esaki, 2002). The Cys625 expressed from MAP2120c is the critical catalytic residue based on studies performed with other bacterial desulfurases (Zheng et al., 1993). The inherent toxicity of free sulfide suggests the biogenesis of sulfur-containing co-factors is mediated by specific protein complexes (Mihara and Esaki, 2002) and perhaps complex I containing the major membrane protein. Furthermore, both these genes are arranged in tandem on the MAP chromosome (Bannantine and Paustian, 2006), and could be present in the same operon.

A protein homologous to MMP has also been found in Mycobacterium leprae. Patients with leprosy were demonstrated to have both an antibody and an IFN- $\gamma$ secreting Tcell proliferative response to this antigen (Triccas et al., 1996). More recently, Shin et al. (2013) observed high antibody titers to MAV2054, a protein with $100 \%$ sequence homology to MMP, in patients with M. avium-Mycobacterium intracellulare complex (MAC) pulmonary disease and pulmonary tuberculosis. Data from the present study also suggests that MMP is a major antigen of MAP, having elicited both an antibody and an IFN- $\gamma$ response in infected animals.

Cysteine desulfurase (MAP2120c) showed the highest antibody recognition among animals across all infection stages and was among the highest in IFN- $\gamma$ response. Collectively, these data suggest that complex I may be important in the pathogenesis of MAP and contain immunodominant antigens of this pathogen.

A protein in complex II was Cfp29 (MAP0630c), the mycobacterial homologue of linocin, a bacteriocin first identified in Brevibacterium linens (Valdes-Stauber and Scherer, 1996). Cfp29 was found in the culture filtrate as well as membrane fractions of Mycobacterium tuberculosis and was demonstrated to be a strong $\mathrm{T}$ cell antigen triggering the release of large quantities of IFN- $\gamma$ from memory effector cells isolated during the recall of protective immunity in the mouse model of TB infection (Rosenkrands et al., 1998). In this study, Cfp29 also demonstrated strong $\mathrm{T}$ cell responses, eliciting high IFN$\gamma$ responses in subclinical animals. Also in complex II, a dye-decolorizing peroxidase (Dyp) type protein (MAP0631c) that is part of a novel family of heme peroxidases was found. Although little research has been done regarding their function, this family of proteins appears to comprise bifunctional enzymes with hydrolase or oxygenase, as well as typical peroxidase activities (Sugano, 2009). The interaction of these two proteins was predicted by String 9.05 due to co-occurrence in other organisms as well as tandem location of coding sequences within the genome. Considering the immune response to Cfp29 in animals infected with MAP characterized in this study, as well as the previous description of reactivity to this protein in tuberculosis infection (Rosenkrands et al., 1998), it is interesting to note that again an antigenic protein is found to be part of a complex. This provides clues as to the function of Cfp29 and how it may be structurally presented to the host during infection.

Proteins of the succinate dehydrogenase complex were identified in complex III. This 4-subunit complex contains proteins involved in the citric acid cycle and in oxidative phosphorylation. In this study, the flavoprotein (MAP3698c) and iron-sulfur (MAP3967c) subunits of the complex were found. Upon studying membrane complexes of M. tuberculosis, Zheng et al. (2011) also found the flavoprotein and iron-sulfur subunits of this complex 

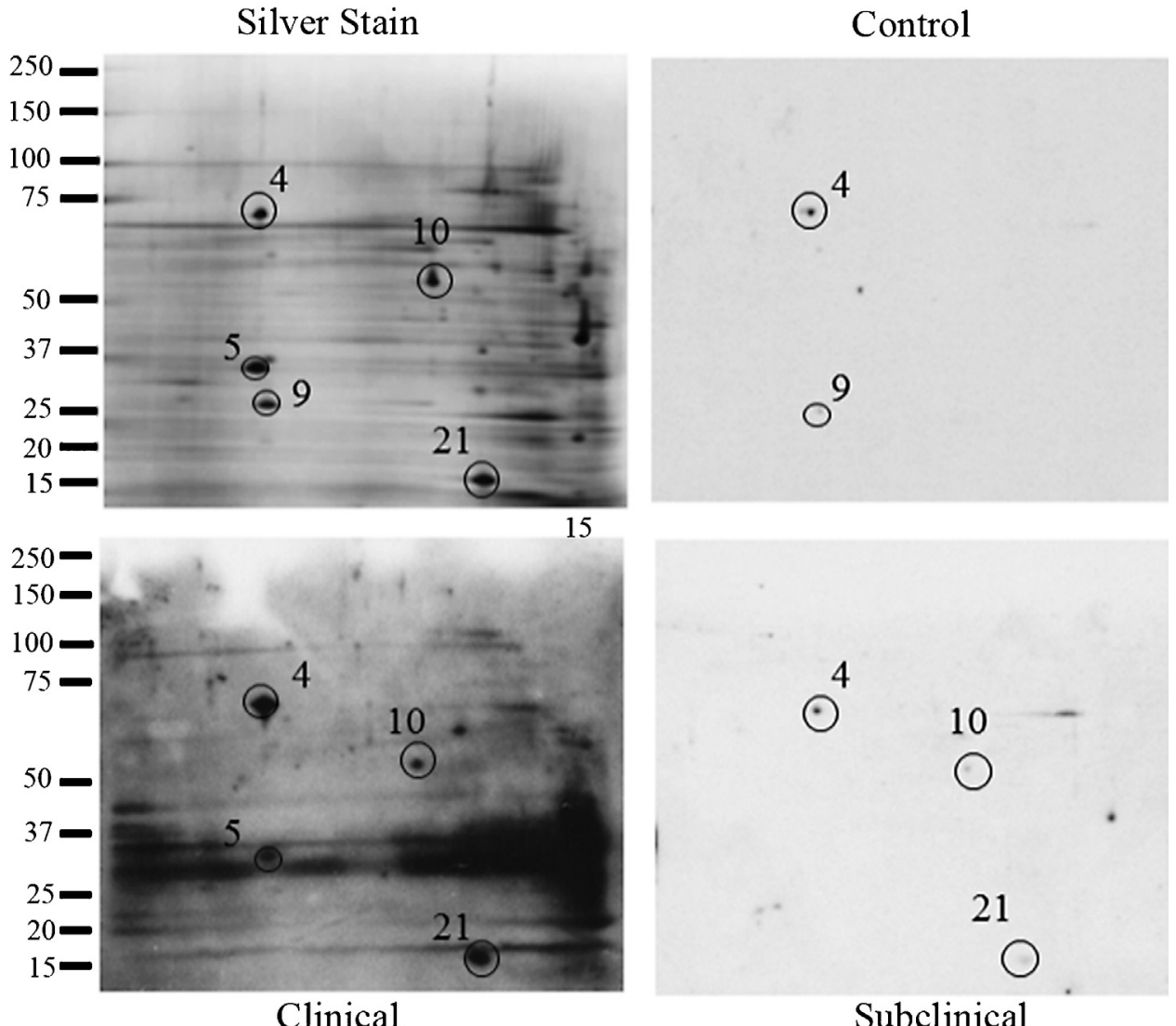

Fig. 4. Representative immunoblot of each cow infection group along with silver stain reference 2D gel. Main proteins recognized are identified as 4: cysteine desulfurase (MAP2120c), 5: major membrane protein (MAP2121c), 9: Cfp29 (MAP0630c), 10: Mpt64 (MAP3290c), 21: bacterioferritin (MAP1595c).

associated with the mycobacterial envelope. In the present study, another succinate dehydrogenase subunit was found encoded by MAP3443. Other subunits of the succinate dehydrogenase complex found in the genome have genes located in the same region and are encoded by MAP3442, MAP3441 and MAP3444. This suggests that MAP may contain two different succinate dehydrogenase complexes.
Glutamine synthetase (MAP1962) plays an essential role in the metabolism of nitrogen by catalyzing the reaction to convert glutamate and ammonia to form glutamine and can form complexes of several identical subunits. In pathogenic mycobacteria, glutamine synthetase has been implicated as having a role in retarding phagosome acidification and phagosome-lysosome fusion (Harth et al., 1994). Additionally, it is believed to be

Table 3

Protein spots reactive on 2D gels revealed by Western-blot with sera from control, subclinical and clinical cows.

\begin{tabular}{|c|c|c|c|c|c|}
\hline \multirow[t]{2}{*}{ Spot \# } & \multirow[t]{2}{*}{ Protein description } & \multirow[t]{2}{*}{ Coding sequence } & \multicolumn{3}{|l|}{$\%$ positive $^{a}$} \\
\hline & & & Control $(n=10)$ & Subclinical $(n=9)$ & Clinical $(n=13)$ \\
\hline 4 & Probable cysteine desulfurase & MAP2120c & 100 & 77.8 & 100 \\
\hline 21 & Bacterioferritin & MAP1595c & 60 & 55.6 & 92.3 \\
\hline 10 & Mpt64 & MAP3290c & 40 & 44.4 & 61.5 \\
\hline 5 & Major membrane protein & MAP2121c & 10 & 22.2 & 61.5 \\
\hline 33 & No ID & & 20 & 22.2 & 15.4 \\
\hline 1 & No ID & & 20 & 33.3 & 38.5 \\
\hline 28 & Acyl-CoA dehydrogenase & MAP0150 & 20 & 33.3 & 7.6 \\
\hline 6 & No ID & & 0 & 11.1 & 7.6 \\
\hline 20 & Putative ATPase & MAP3844 & 0 & 0 & 15.4 \\
\hline 9 & Linocin/Cfp29 & MAP0630c & 40 & 33.3 & 7.6 \\
\hline
\end{tabular}

a \% positive is defined as the number of serum samples that reacted positively with the designate protein on Western-blot of total serum samples tested within that infection group. 


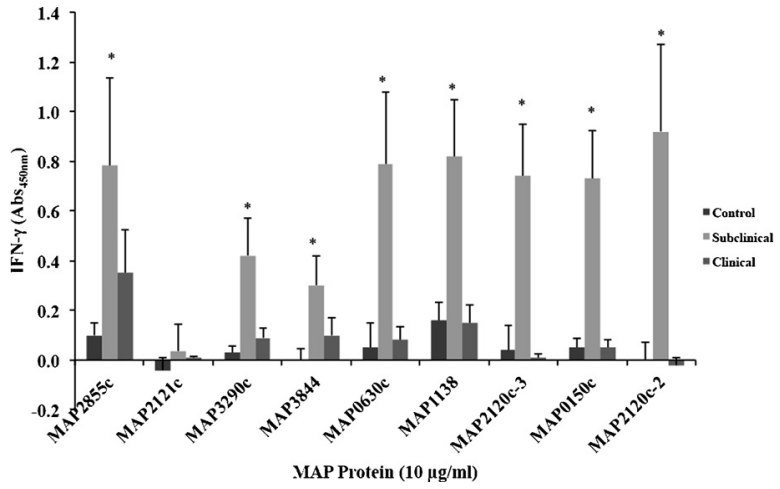

Fig. 5. Interferon-gamma responses measured by ELISA after incubation of whole blood from cows in control noninfected $(n=5)$, subclinical $(n=5)$, and clinical $(n=6)$ infection status with recombinant proteins $(10 \mu \mathrm{g} / \mathrm{ml})$. Data are presented as mean \pm SEM. Asterisk $\left(^{*}\right)$ depicts significant differences for subclinical cows compared to other treatment groups $(P<0.05)$.

involved in cell wall biosynthesis with the production of poly-L-glutamate-glutamine that is a major component of the cell wall in pathogenic mycobacteria (Chandra et al., 2010), suggesting a major role in host-pathogen interactions during infection.

Several of the proteins found to be members of a complex were encoded by tandemly located genes that may be part of the same operon. As mentioned above, some of these proteins have known functions that are synergistic with other members of the same complex, as is the case with the succinate dehydrogenase subunits encoded by MAP3697c and MAP3698c. We acknowledge that proteins may be co-expressed in an operon but not assembled into a true biological complex, although to the best of our knowledge, there is no published evidence for this. However, such co-expressed proteins that have no true interaction with each other, would not likely remain together following blue native gel electrophoresis in the conditions we used. Furthermore, the protein complex containing proteins encoded by MAP2120 and MAP2121c, which are co-located on the genome and may be part of the same operon do in fact form a complex. These proteins were identified by MS in the band corresponding to their complex in blue native page gel and with denaturation were resolved in the second dimension SDS-PAGE gel. This demonstrates that these two proteins have an interaction in the same protein complex, as evidenced by their presence in the same BN-PAGE gel band and by their alignment in the second dimension SDS-PAGE gel.

Several proteins had greater reactivity in the subclinical group as compared to clinical animals and control animals in the IFN- $\gamma$ assay, suggesting they may be good diagnostic targets when used in this assay. Among these proteins was phage shock protein A (MAP2855). This protein is part of the phage-shock protein response (Psp), a conserved system of many bacteria to respond to extracellular stress. In some pathogens such as Salmonella typhimurium, phage shock protein A (PspA) has been demonstrated to be essential for virulence and survival of the bacterium inside the macrophage (Darwin, 2013). This protein demonstrated high reactivity in subclinical animals even at the lowest concentration (data not shown).

MAP3290c encodes Mpt64, a protein characterized as an immune-dominant secreted antigen from $M$. tuberculosis. Several diagnostic assays for human tuberculosis have been developed using this protein, including immune-chromatographic assays to test for the protein in bacterial cultures, immunohistochemistry to identify the protein in tissues, and ELISA for detection of serum antibodies in infected patients (Yin et al., 2013). In the present study, Mpt64 was shown to be a strong $\mathrm{T}$ cell antigen with IFN- $\gamma$ responses, as well as high reactivity in Western blots, demonstrating promise as a candidate for diagnostic development. Chen et al. (2012) investigated a mutant strain of MAP with a MAP3290c gene deletion as an attenuated vaccine for paratuberculosis. The deletion resulted in a more rapid elimination of the bacterium in mice in comparison to the wild-type strain, suggesting Mpt64 has an important role in pathogenesis.

Table 4

Band intensity of proteins reacted against sera from control non-infected animals $(n=5)$, subclinical $(n=7)$ and clinical $(n=5)$.

\begin{tabular}{|c|c|c|c|}
\hline \multirow[t]{2}{*}{ Protein ID } & \multicolumn{3}{|l|}{ Infection status } \\
\hline & Control & Subclinical & Clinical \\
\hline Cysteine desulfurase-2, MAP2120c & $2389( \pm 711)$ & $330( \pm 216)$ & $9758( \pm 3096)$ \\
\hline Cysteine desulfurase-3, MAP2120c & $708( \pm 343)$ & $181( \pm 101)$ & $6958( \pm 2741)$ \\
\hline Linocin/Cpf59, MAP0630c & $17( \pm 16) a$ & $398( \pm 280) a$ & $2449( \pm 914) b$ \\
\hline Bacterioferritin, MAP1595 & $2379( \pm 1032)$ & $196( \pm 194)$ & $6931( \pm 3421)$ \\
\hline Major membrane protein, MAP2121c & $1019( \pm 571)$ & $413( \pm 155)$ & $6303( \pm 3024)$ \\
\hline Acyl-CoA dehydrogenase, MAP0150 & $413( \pm 268) a$ & $455( \pm 448) \mathrm{a}$ & $3402( \pm 1403) b$ \\
\hline Putative ATPase, MAP3844 & $1015( \pm 920)$ & $1506( \pm 1197)$ & $3573( \pm 2487)$ \\
\hline Mpt64, MAP3290c & $4542( \pm 4466)$ & $72( \pm 48)$ & $944( \pm 925)$ \\
\hline Phage shock protein A, MAP2855c & $121( \pm 77)$ & $1706( \pm 846)$ & $5116( \pm 3768)$ \\
\hline 22 kDa lipoprotein, MAP1138c & $2( \pm 2) a$ & $12( \pm 7) \mathrm{a}$ & $708( \pm 708) b$ \\
\hline MAP whole-cell sonicate & $51( \pm 24) a$ & $1900( \pm 1869) a$ & $5356( \pm 2201) b$ \\
\hline MAP envelope preparation & $999( \pm 522)$ & $1274( \pm 555)$ & $9066( \pm 3365)$ \\
\hline
\end{tabular}

Different letters within a row indicate statistical significance $(P<0.05)$ for protein expression between treatment groups. Band intensity of each protein was measured after subtracting background of maltose binding protein control reactivity within the same serum sample. If a negative value was obtained it was substituted with the value of zero.

a Representative mean band intensities for all animals within an infection group and standard errors of the mean in parentheses. 


\section{Conclusions}

The present study is the first to investigate protein complexes in the envelope of MAP. Seven putative protein complexes were found along with the identification of several novel antigenic proteins. The finding that some proteins such as MMP (MAP2121c) and Cfp29 (MAP0630c) are part of complexes provides some information as to their interactions with other proteins and possible associations with bacterial virulence. Some proteins, such as MMP (MAP2121c) demonstrated antigenicity dependent upon stage of infection, suggesting they are differentially regulated during the course of infection. This study illuminates an important compartment of MAP, the cell envelope, that is crucial for the pathogenesis of the bacterium and likely holds the initial antigens the host encounters upon infection.

\section{Conflict of interest}

None.

\section{Acknowledgments}

The authors wish to thank Adrienne Staple, Janis Hansen, Margaret Walker, and Livia Eslabão for their technical help with this study. This work was funded by the USDA-Agricultural Research Service.

\section{Appendix A. Supplementary data}

Supplementary data associated with this article can be found, in the online version, at http://dx.doi.org/10.1016/ j.vetmic.2014.11.009.

\section{References}

Bannantine, J.P., Paustian, M.L., 2006. Identification of diagnostic proteins in Mycobacterium avium subspecies paratuberculosis by a whole genome analysis approach. Methods Mol. Biol. 345, 185-196.

Bannantine, J.P., Huntley, J.F., Miltner, E., Stabel, J.R., Bermudez, L.E., 2003. The Mycobacterium avium subsp. paratuberculosis $35 \mathrm{kDa}$ protein plays a role in invasion of bovine epithelial cells. Microbiology 149, 2061-2069.

Bannantine, J.P., Stabel, J.R., Bayles, D.O., Geisbrecht, B.V., 2010. Characteristics of an extensive Mycobacterium avium subspecies paratuberculosis recombinant protein set. Protein Express. Purif. 72, 223-233.

Chandra, H., Basir, S.F., Gupta, M., Banerjee, N., 2010. Glutamine synthetase encoded by $\operatorname{gn} A-1$ is necessary for cell wall resistance and pathogenicity of Mycobacterium bovis. Microbiology 156, 3669-3677.

Chen, J.W., Faisal, S.M., Chandra, S., McDonough, S.P., Moreira, M.A., Scaria, J., Chang, C.F., Bannantine, J.P., Akey, B., Chang, Y.F., 2012. Immunogenicity and protective efficacy of the Mycobacterium avium subsp. paratuberculosis attenuated mutants against challenge in a mouse model. Vaccine 30, 3015-3025.

Darwin, A.J., 2013. Stress relief during host infection: the phage shock protein response supports bacterial virulence in various ways. PLoS Pathog. 9 , http://dx.doi.org/10.1371/journal.ppat.1003388.

Deng, W., Xie, J., 2012. Ins and outs of Mycobacterium tuberculosis PPE family in pathogenesis and implications for novel measures against tuberculosis. J. Cell. Biochem. 113, 1087-1095.

Dresler, J., Klimentova, J., Stulik, J., 2011. Bacterial protein complexes investigation using blue native PAGE. Microbiol. Res. 166, 47-62.

Facciuolo, A., Kelton, D.F., Mutharia, L.M., 2013. Novel secreted antigens of Mycobacterium paratuberculosis as serodiagnostic biomarkers for Johne's disease in cattle. Clin. Vaccine Immunol. 20, 1783-1791.

Harth, G., Clemens, D.L., Horwitz, M.A., 1994. Glutamine synthetase of Mycobacterium tuberculosis: extracellular release and characteriza- tion of its enzymatic activity. Proc. Natl. Acad. Sci. U. S. A. 91, 9342-9346.

He, Z., De Buck, J., 2010. Localization of proteins in the cell wall of Mycobacterium avium subsp. paratuberculosis K10 by proteomic analysis. Proteome Sci. 8, 8-21.

Keller, A., Nesvizhskii, A.I., Kolker, E., Aebersold, R., 2002. Empirical statistical model to estimate the accuracy of peptide identifications made by MS/MS and database search. Anal. Chem. 74, 5383-5392.

Khalifeh, M.S., Al-Majali, A.M., Stabel, J.R., 2009. Role of nitric oxide in dairy cows naturally infected with Mycobacterium avium subsp. paratuberculosis. Vet. Immunol. Immunopathol. 131, 97-104.

Kleinnijenhuis, J., Oosting, M., Joosten, L.A., Netea, M.G., Van Crevel, R., 2011. Innate immune recognition of Mycobacterium tuberculosis. Clin. Dev. Immunol. 2011, 405310, http://dx.doi.org/10.1155/2011/405310.

Li, L., Bannantine, J.P., Zhang, Q., Amonsin, A., May, B., Alt, D., Banerji, N., Kanjilal, S., Kapur, V., 2005. The complete genome sequence of Mycobacterium avium subspecies paratuberculosis. Proc. Natl. Acad. Sci. U. S. A. 102, 12344-12349.

Lombard, J.E., 2011. Epidemiology and economics of paratuberculosis Vet. Clin. N. Am. Food Anim. Pract. 27, 525-535.

Mihara, H., Esaki, N., 2002. Bacterial cysteine desulfurases: their function and mechanisms. Appl. Microbiol. Biotechnol. 60, 12-23.

Mortier, R.A., Barkema, H.W., Wilson, T.A., Sajobi, T.T., Wolf, R., De Buck, J., 2014. Dose-dependent interferon-gamma release in dairy calves experimentally infected with Mycobacterium avium subspecies paratuberculosis. Vet. Immunol. Immunopathol. 161, 205-210.

Nesvizhskii, A.I., Keller, A., Kolker, E., Aebersold, R., 2003. A statistical model for identifying proteins by tandem mass spectrometry. Anal. Chem. 75, 4646-4658.

Niederweis, M., Danilchanka, O., Huff, J., Hoffmann, C., Engelhardt, H., 2010. Mycobacterial outer membranes: in search of proteins. Trends Microbiol. 18, 109-116.

Radosevich, T.J., Reinhardt, T.A., Lippolis, J.D., Bannantine, J.P., Stabel, J.R., 2007. Proteome and differential expression analysis of membrane and cytosolic proteins from Mycobacterium avium subsp. paratuberculosis strains K-10 and 187. J. Bacteriol. 189, 1109-1117.

Reinhardt, T.A., Lippolis, J.D., Nonnecke, B.J., Sacco, R.E., 2012. Bovine milk exosome proteome. J. Proteomics 75, 1486-1492.

Rosenkrands, I., Rasmussen, P.B., Carnio, M., Jacobsen, S., Theisen, M., Andersen, P., 1998. Identification and characterization of a 29-kilodalton protein from Mycobacterium tuberculosis culture filtrate recognized by mouse memory effector cells. Infect. Immun. 66, 2728-2735.

Schägger, H., Jagow, G., 1991. Blue native electrophoresis for isolation of membrane protein complexes in enzymatically active form. Anal. Biochem. 199, 223-231.

Schamel, W.W., 2008. Two-dimensional blue native polyacrylamide gel electrophoresis. Curr. Protoc. Cell. Biol., http://dx.doi.org/10.1002/ 0471143030.cb0610s38.

Scott, M.C., Bannantine, J.P., Kaneko, Y., Branscum, A.J., Whitlock, R.H., Mori, Y., Speer, C.A., Eda, S., 2010. Absorbed EVELISA: a diagnostic test with improved specificity for Johne's disease in cattle. Foodborne Pathog. Dis. 7, 1291-1296.

Shin, A., Lee, K., Lee, K.I., Shim, T.S., Koh, W., Jeon, H.S., Son, Y., Shin, S., Kim, H., 2013. Serodiagnostic potential of Mycobacterium avium MAV2054 and MAV5183 proteins. Clin. Vaccine Immunol. 20, 295-301.

Stabel, J., 1998. Johne's disease: a hidden threat. J. Dairy Sci. 81, 283-288.

Stabel, J.R., 2006. Host responses to Mycobacterium avium subsp. paratuberculosis: a complex arsenal. Anim. Health Res. Rev. 7, 61-70.

Sugano, Y., 2009. DyP-type peroxidases comprise a novel heme peroxidase family. Cell. Mol. Life Sci. 66, 1387-1403.

Sweeney, R.W., 2011. Pathogenesis of paratuberculosis. Vet. Clin. N. Am. Food. Anim. Pract. 27, 537-546.

Triccas, J.A., Roche, P.W., Winter, N., Feng, C.G., Butlin, C.R., Britton, W.J., 1996. A 35-kilodalton protein is a major target of the human immune response to Mycobacterium leprae. Infect. Immun. 64, 5171-5177.

Valdes-Stauber, N., Scherer, S., 1996. Nucleotide sequence and taxonomical distribution of the bacteriocin gene lin cloned from Brevibacterium linens M18. Appl. Environ. Microbiol. 62, 1283-1286.

Yin, X., Zheng, L., Lin, L., Hu, Y., Zheng, F., Hu, Y., Wang, Q., 2013. Commercial MPT64-based tests for rapid identification of Mycobacterium tuberculosis complex: a meta-analysis. J. Infect. 67, 369-377.

Zheng, J., Wei, C., Zhao, L., Liu, L., Leng, W., Li, W., Jin, O., 2011. Combining blue native polyacrylamide gel electrophoresis with liquid chromatography tandem mass spectrometry as an effective strategy for analyzing potential membrane protein complexes of Mycobacterium bovis bacillus Calmette-Guérin. BMC Genomics 12 (40), http:// dx.doi.org/10.1186/1471-2164-12-40.

Zheng, L., White, R.H., Cash, V.L., Jack, R.F., Dean, D.R., 1993. Cysteine desulfurase activity indicates a role for NIFS in metallocluster biosynthesis. Proc. Natl. Acad. Sci. U. S. A. 90, 2754-2758. 